\title{
Social Media for Collaborative Learning and Engagement: Adoption Framework in Higher Education Institutions in Malaysia
}

\author{
Waleed Mugahed Al-rahmi \\ Mohd Shahizan Othman \\ Lizawati Mi Yusuf \\ Department of Information System, Faculty of computing, Universiti Teknologi Malaysia, Johor Bahru, 81310, Malaysia \\ Email: abumunir82@yahoo.com
}

\section{Doi:10.5901/mjss.2015.v6n3s1p246}

\begin{abstract}
This paper addresses collaborative learning and engagement via intention towards social media use that have been tackled by some researches in terms of its impacts on students' academic performance. However, only a few of such studies have been carried out in the area of collaborative and engagement use of social media for enhancing researchers'/students' performance. The present study attempts to determine the way social media can be utilized to enhance researchers' performance via collaborative and engagement by applying the theory of technology acceptance model (TAM) along with constructivism theory. According to the results, collaborative learning and engagement positively and significantly impact perceived ease of use (PE), perceived usefulness (PU), and intention to use social media (IU) through the social media use in the context of Universiti Teknologi, Malaysia.
\end{abstract}

Keywords: Social media use, TAM theory, collaborative learning, engagement, and higher education.

\section{Introduction}

The development of social media network and web 2.0 technologies has been monumental (Lenhart et al., 2010), where social media technology has managed to disseminate into the every aspect of the users' personal life in terms of contributing content, sharing photos, liking comments or contents or game interaction. Such dissemination is specifically evident in institutions of higher learning where technology has changed students' communication, collaboration and learning. In this regard, social media can be described as the several technological systems that are linked to both collaboration and community (Joosten, 2012). Despite the fact that researchers have not reached a consensus on an accurate definition of the term (Kaplan \& Haenlein, 2010), social media is often viewed through examples like social networking sites, blogs, Wikis, multimedia platforms and virtual social worlds (Barnes \& Lescault, 2011). This paper concentrates on the networking sites reflecting the permeating existence of social media like Facebook, Myspace and LinkedIn. In fact social networking sites are utilized similar to social networking or online social networks and are based on the web allowing users to create their personal profiles, content, and share messages by connecting with other uses of the system (Boyd \& Ellison, 2007). Other studies use a more up-to-date term called the web 2.0 when addressing both social network and other social media (Gruzd, 2011). This study is aimed to examining the relationship between intention to use social media for collaborative learning and engagement among students at universities. The rest of the paper is organized as follows: section two: describes about types of social media used for academic purpose, section three: describes about research method, section four: describes about conceptual framework and hypotheses and last section number five: describes about results, discussion, conclusion and future work.

\section{Types of Social Media Use for Academic Purpose}

Social media can be used by the academicians through different ways, several which is described below;

\subsection{Facebook}

Facebook is the most widely used social networking sites in terms of being an instructional tool in the higher institutions 
classrooms. Specifically, Irwin et al. (2012) examined Facebook use under four specific university courses whereas McCarthy (2010) stated that Facebook is an ideal host site for the combination of learning and environment. The latter studied five-year elective course administered to 120 architecture students. His findings revealed that $95 \%$ of the respondents agree that they use Facebook to develop relationships with peers while $92 \%$ akconwledged the interactive discussions with peers in virtual classrooms. In this regard, McCarthy (2010) demonstrated that heightened course engagement particularly in terms of assessment tasks as shown by the Facebook activity logs. Despite the successes, a few studies advised against its extensive use; for instance, Madge et al. (2009) stated that Facebook is questionable when it comes to carrying out actual pedagogical activities.

\subsection{Blogs}

Blogs are other widely acknowledged and utilized networking sites on a global scale and this is the reason why an indepth examination has been conducted on it by several authors on it in the context of higher education. Majority of such studies were dependent on self-reported data gathered through surveys and interviews, and analysis of blog content in order to reach conclusions. As with the study conducted by Sim \& Hew (2010), the present work explored blogs in an higher educational environment. In a related study, Deng and Yuen (2011) carried out a survey involving 37 student teachers in Hong Kong regarding their experiences with the inclusion of blogs into their daily activities. The study also brought forwards a framework for educational affordances of blogs. Also, Top (2012) investigated the teachers' community perception of blogging courses from the perspective of pre-service teachers. Blogs were also examined in terms of a sophomore course called 'data structure' in a university in Taiwan by Huang et al. (2011).

\subsection{Twitter}

A thorough review of literature shows that experimental studies were dedicated to examining the effect of social media upon learner engagement and achievement. Specifically, Borau (2009) described twitter users' experienced in terms of using the system as a training tool for communication and cultural competence in the class. Also, Dunlap and Lowenthal (2009) described twitter inclusion experience into online instructional design and technology class.

\subsection{Linkedln}

Linkedln is a networking site that is primarily utilized for professional networking, introduced in May 2003. Linkedln users are connected with others in their employ, and they maintain contacts that they know and trust in businesswise. This system is based on the premise that social networking is linking with others that required relationship building and communication (Papacharissi, 2009). In the context of the U.S., Linkedln users have achieved its $35,000,000$ user mark and it has been shown to be the top three of the most visited networking sites as reported by ComScore (2011).

\section{Research Method}

In this study, data was gathered through a survey questionnaire distributed among 323 post-graduate students in the year 2013/2014. Students were instructed in the questionnaire to offer information about their experiences with the social media tools. In the present research, a quantitative approach (positivism paradigm) was used to test concluded hypotheses empirically. The respondents were aged between 18 and above 35. The actual sample comprised of 151 male respondents and 172 female respondents. The sample was requested to complete the survey and provide information concerning their experiences of using social media and its impact on collaborative learning. A quantitative method was used involving student studying in University Teknologi Malaysia.

\subsection{Respondents}

A total of 323 set of questionnaires were distributed in a random manner to undergraduate and post-graduate University Teknologi Malaysia students. Data was analyzed with the help of IBM SPSS (Version-20) and Amos (Version-16). The study factors were developed on the basis of the research aims and the obtained Cronbach's alpha of reliability and validity of the instrument was found to be 0.917 . This value is acceptable and evidenced the reliability requirement of the study instrument. The developed questions were easy to understand and the questionnaire was divided into five sections for clarification of questions. 


\subsection{Data collection procedures}

The questionnaire adopted the five-point Likert scale with 1 depicting strongly disagree and 5 depicting strongly agree. A pilot study was conducted prior to the actual one to fine-tune the questionnaire and to gather the opinions and feedback of the students regarding the use of social media impact on collaborative learning, examined with the help of TAM theory in one of the institutions of higher learning in Malaysia. The survey included 31 items and was designed, revised and distributed among students at the end of the 2013/2014 semester. Every participant was provided the study background. The thirty one items designed attempted to measure the constructs in the study framework; specifically, a subset of sixteen items adopted form Kwon and Wen (2010) measured perceived ease of use and perceived usefulness, eight items adopted from Kim et al. (2008) measured social media use, seven items adopted from Al-Rahmi and Othman (2013a) measured collaborative learning and three items adopted from Medlin \& Green (2009) measured engagement. The constructs were represented by the following acronyms; perceived ease of use (PE), perceived usefulness (PU), intention to use social media (IU), collaborative learning (CL) and lastly, engagement (EN).

\section{Conceptual Framework and Hypotheses}

The primary aim behind the present study is to develop a framework emphasizing the effect of social media use on collaborative learning and engagement among students at the university level through the technology acceptance model (TAM) in the context of the Universiti Teknologi Malaysia (Fig. 1). It is suggested that students' perceived ease of use, perceived usefulness, collaborative learning and engagement from social media use promotes their use, which in turn, leads to improved active collaborative learning and engagement. The present research evidenced that social media inclusion is linked to collaborative learning and engagement among students and researchers, where the variables include perceived ease of use (PE), perceived usefulness (PU), intention to use social media (IU), collaborative learning (CL and lastly, engagement (EN).

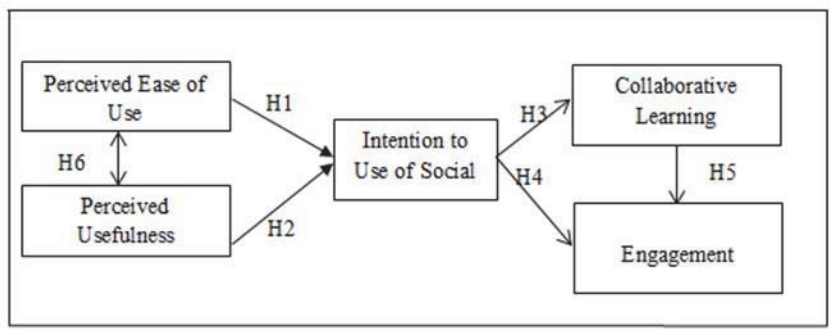

Fig 1: Conceptual Framework

It is without a doubt, as evidenced by several studies that social media maximizes the perceived interaction quality within the class in twofold - among students and among students and teachers (Ajjan \& Hartshorne, 2008). Such interaction is a key aspect in the training process and it motivates learners acceptance of collaborative learning (So \& Brush, 2008), which in turn, highlights their perceived ease of use, perceived usefulness, and perceived enjoyment (Kim et al., 2007). All the latter three constructs improve students' intention towards social media use and collaborative learning among students and researchers in institutions of higher learning.

\subsection{Perceived Usefulness and Perceived East of Use}

The technology acceptance model (TAM) was adapted from the theory of reasoned action (TRA). It posits that perceived usefulness and perceived ease of use determine the intention the system, where such intention serves as a mediating variable of actual system use. To this end, perceived usefulness is considered to be directly affected by perceived ease of use. The researchers have summarized TAM by excluding the attitude construct originally included in TRAM (Venkatesh, et al., 2003). TAM provides a description of the individual's behavioral intention regarding the application's use, which is described by perceived usefulness and perceived ease of use. Following its introduction by Davis et al. (1989), TAM has been extensively utilized in studies to predict the use of information technologies (Selim, 2003). Davis et al. (1989) stated that perceived usefulness of social media network as well as perceived ease of use of the social media network determines the user's intention towards social media network use. TAM also describes the relationship between 
social media network design variables, perceived usefulness of the social media network, perceived ease of its use, individual's attitudes towards its use in higher education. On the basis of the above argument, the first hypothesis is developed as follows;

H1: there's a significant relationship between perceived ease of use and intention to use social media.

$\mathrm{H} 2$ : there's a significant relationship between perceived usefulness and intention to use social media.

H6: there's mutual a significant relationship between perceived ease of use and perceived usefulness.

\subsection{Intentions towards Social Media Use}

The intention towards social media network among students in collaborative learning holds the key factors in structure technology use models (Venkatesh et al., 2003; Davis et al., 1989) with the theories extended form the fundamental principles of TRA. Such principles consider intention to use the system as the function of attitude towards individual behavior and subjective norms that were extended to TPB (Venkatesh \& Bala, 2008). In this regard, Moon and Kim (2001) claimed that individuals who find enjoyment in using a web system will perceive positive interactions and form greater behavioral intention to use it. According to this argument, the second and third hypotheses are developed as follows;

H3: there's a significant relationship between intention to use social media and collaborative learning.

H4: there's a significant relationship between intention to use social media and engagement.

\subsection{Collaborative Learning}

A great and extensive acceptance and integration of social media has been achieved into pedagogical aspects in the last few years. Nevertheless, the social media effectiveness in enhancing academic performance in terms of collaborative learning has been noted to have increased. According to extant studies, social media is an invaluable tool that improves students' academic performances (e.g. Selwyn et al., 2009; Al-Rahmi \& Othman, 2013a). Additionally, collaborative learning with the assistance of social media like Facebook, e-mail, twitter, to name a few, encourages learning and knowledge sharing among students, teachers, and instructors alike in real life circumstances. Added to this, it should be kept in mind that the primary determinants of the students' inclination towards collaborative learning with social media network are the amount of cognitive level that a learning task requires on the learners' cognitive capacity, and hence, such cognitive capacity effects may lead to the erroneous conclusion that results of social media support collaborative learning (SSCL) are effective (Hung \& Yuen, 2010; Al-Rahmi \& Othman, 2013b). Based on the above argument, the following hypothesis is proposed;

H5: there's a significant relationship between collaborative learning and engagement.

\subsection{Engagement}

Two prior studies addressed social media and engagement and the relationship between time spent on social media and student engagement as first proposed by Astin (1984). First, Heiberger and Harper (2008) conducted a study involving 377 undergraduate students enrolled in Midwestern institution and second, study involved fist year college students who participated in data collection. The students numbered 31,000 studying in 114 colleges and universities. The results of both studies highlighted a positive relationship between social networking sites use and engagement of college students. Also, the Higher Education Research (2007) showed that a higher percentage of high uses of social networking websites participated in campus organizations in comparison to the lower users. Majority of users also reported high daily interaction with peers and felt that their connection has been reinforced.

\section{Results and Discussion}

The respondents' backgrounds were obtained from the questionnaire collected data, where the distribution of respondents was based on the basic sample demographic. First, the number of respondents in terms of gender equals 151 male respondents (46.7\%) and 172 female respondents (53.3\%) - the number of the latter exceeds the former - but such occurrence was not done deliberately. Second, the respondents ages are -42 respondents fell on the 21-24 years old group (13.0\%), 138 respondents fell on the 25-30 years old group, 88 fell to the $30-35$ years old group (27.2\%) and 55 were above 35 years old (17.0\%). On the basis of their degrees, 49 respondents (15.2\%) had a full master degree, 51 respondents $(16.1 \%)$ had a master mixed mode degree, 80 respondents $(24.7 \%)$ had master-taught course, 138 
respondents (42.7\%) had PhD and 4 respondents (1.2\%) had post-doctoral degrees.

\subsection{Results of Hypotheses Testing}

The results obtained by the analysis of data showed support for the study hypothesis concerning the relationship direction between the variables in the study framework. Table 1 presents the values of parameter unstandardized coefficients and standard errors for the structural framework.

Table 1: Regression weights

\begin{tabular}{|c|c|c|c|c|c|c|c|c|}
\hline $\mathrm{H}$ & Independent & Relationship & Dependent & Estimate & S.E. & C.R. & $\mathbf{P}$ & Result \\
\hline $\mathrm{H} 1$ & $\mathrm{PE}$ & & IU & .356 & .058 & 6.152 & $\star \star \star *$ & Supported \\
\hline $\mathrm{H} 2$ & $\mathrm{PU}$ & & IU & .319 & .056 & 5.713 & $\star \star \star *$ & Supported \\
\hline $\mathrm{H} 3$ & $\mathrm{IU}$ & & $\mathrm{CL}$ & .729 & .052 & 14.02 & 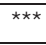 & Supported \\
\hline $\mathrm{H} 4$ & $\mathrm{IU}$ & $>$ & EN & .300 & .050 & 5.947 & 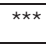 & Supported \\
\hline $\mathrm{H} 5$ & $\mathrm{CL}$ & & EN & .501 & .043 & 11.75 & $\star * \star *$ & Supported \\
\hline $\mathrm{H} 6$ & PU & $<$ & $\mathrm{PE}$ & .340 & .031 & 10.94 & 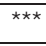 & Supported \\
\hline
\end{tabular}

C.R.: critical ratio or t-value

Table 1 and figure two show that intention towards social media use positively and significantly related with collaborative learning ( $\beta 2=0.729, p<0.001)$ and as such, hypothesis $3(\mathrm{H} 3)$ is supported. Table 1 also shows that collaborative learning positively and significantly relates with engagement $(\beta 3=0.501, p<0.001)$ and as such, hypothesis five $(H 5)$ is also supported. In other words, group members or supervisor discussions will enhance performance of researchers as supported by social media. Table 1 also confirms that perceived ease of use positively and significantly related with intention to use social media $(\beta 3=0.356, p<0.001)$ - this evidences that hypothesis one $(\mathrm{H} 1)$ is supported. Therefore, researchers use social media for information sharing or collaborative learning. Hypothesis six (H6) was also supported as perceived usefulness was found to be positively and significantly related with perceived ease of use $(\beta 3=0.340, p<$ 0.001). Intention towards social media use enables the information exchange among researchers, which in turn, maximizes the knowledge sharing capabilities and motivates group members' discussion.

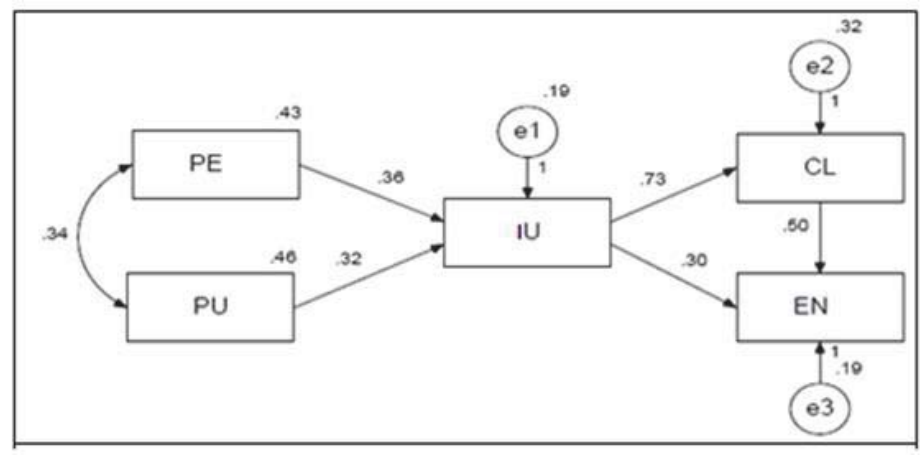

Fig 2: Results for the proposed framework

The findings (See Table 2) also showed that perceived usefulness is positively and significantly related with intention to use social media ( $\beta 3=0.319, p<0.001)$ supporting hypothesis two $(\mathrm{H} 2)$. Researchers in other words, are inclined to use social media for collaborative learning. Lastly, hypothesis four $(\mathrm{H} 4)$ is supported as the results showed that intention to use social media positively and significantly related with engagement $(\beta 3=0.300, p<0.001)$. This explains that researchers are capable of resource and information sharing as collaborative learning improves their academic performance. Parallel to the study outcome of the students' collaborative learning through intention to use social media in institutions of higher learning, the following relevant and related information were highlighted; in satisfaction in social media is brought about by the encouragement and facilitation of students' use of social media for collaborative learning as this could boost their experience and interactivity. Table 2 presents the analyzed relationship between student engagement (EN), perceived ease of use (PE), perceived usefulness (PU), intention to use social media (IU) and 
collaborative learning. Table 1 shows that the Pearson correlation coefficient achieved 99\% confidence level, with the highest correlation found between engagement and perceived ease of use (PE), followed by perceive usefulness (PU) and collaborative learning $(\mathrm{CL})$ with the coefficient being 0.819 (See Table 2).

Table 2: Descriptive statistics and correlation matrix

\begin{tabular}{|c|c|c|c|c|c|}
\hline & PE & PU & IU & CL & EN \\
\hline PE & 1 & & & & \\
\hline PU & $.870^{\star *}$ & 1 & & & \\
\hline $\mathrm{IU}$ & $.760^{\star \star}$ & $.753^{\star *}$ & 1 & & \\
\hline $\mathrm{CL}$ & $.852^{\star \star}$ & $.774^{\star *}$ & $.716^{\star \star}$ & 1 & \\
\hline $\mathrm{EN}$ & $.819^{\star \star}$ & $.819^{\star \star}$ & $.715^{\star \star}$ & $.819^{\star \star}$ & 1 \\
\hline
\end{tabular}

**. Correlation is significant at the 0.01 level (2-tailed).

Pearson correlation results of engagement, evidences that engagement through social media positively and significantly correlates with collaborative learning at $(r=0.819, p<0.01)$. Correlation was also found between engagement and perceived ease of use at $(r=0.819, p<0.01)$, and between researchers' satisfaction and engagement with perceived usefulness at $(r=0.819, p<0.01)$. Lastly, correlation was found between engagement, usefulness and intention to use social media at $(r=0.715, p<0.01)$. Second, the Pearson correlation results of collaborative learning through social media use positively and significantly correlates with perceived ease of use at $(r=0.852, p<0.01)$. Positive and significant correlation was also found between collaborative learning and perceived usefulness at $(r=0.774, p<0.01)$ and between collaborative learning and intention towards using social media at $(r=0.716, p<0.01)$. Third, Pearson correlation results of intention to use social media showed positive and significant correlation of intention to use social media with perceived ease of use at $(r=0.760, p<0.01)$. Positive and significant correlation was also noted between intention to use social media with perceived usefulness at $(r=0.753, p<0.01)$, and between intention to use social media and perceived ease of use at $(r=0.870, p<0.01)$.With regards to collaborative learning and perceived ease of use, a typical percentage was obtained as this study addressed the university level and collaborative learning facilitates knowledge sharing through social media at any time. Social media intention to use and its actual use also obtained an average percentage as social media adds to the confidence of students by enabling them to collaborate between their peers and instructors, and to engage in classroom activities. Lastly, the relationship between collaborative learning and perceived usefulness of social media also obtained average percentage as social media enables communication among teachers and students and lead to enhanced academic performance.

\subsection{Conclusion and Future Work}

Five predictors were examined in this study in terms of collaborative learning and engagement via intention to use social media among researchers; perceived ease of use (PE), perceived usefulness (PU), intention to use social media (IU), collaborative learning $(\mathrm{CL})$ and engagement (EN). According to the results, it can be concluded that social media brings about collaborative learning, engagement and heightened academic experience among the study participants. Future work can tackle factors that impact collaborative learning and engagement in order to enhance researchers' performance while taking demographic factors into consideration. Future work may also involve a larger study sample for the clarification of elements and measurement of factors in the context of institutions of higher learning.

\section{Acknowledgment}

This material is based upon work supported by Instructional Development Grant (IDG) and Research University Grant (RUG) Universiti Teknologi Malaysia, and the Academy of Sciences for the Development World (TWAS) Research Grant under Vote No. 08216,02J 57, and 10-147 RG/ITC/AS_C; UNESCO FR:3240246311. Any opinions, findings, and conclusions or recommendations expressed in this material are those from the authors and do not necessarily reflect on the views of the Universiti Teknologi Malaysia and the Academy of Sciences for the Development World; also supported by Faculty of Marine, Hodeidah University, Hodeidah, Yemen. 


\section{References}

Ajjan H. ,and Hartshorne, R. (2008).Investigating faculty decisions to adopt Web 2.0 technologies: Theory and empirical tests, Internet and Higher Education, 2008.

Al-rahmi,W. and Othman , M. (20133a).Evaluating student's satisfaction of using social media through collaborative learning in higher education. linternational journal of advances in engineering \& technology, 2013.

Al-rahmi,W. and Othman, M. (2013b).The Impact of Social Media use on Academic Per-formance among university students: A Pilot Study. Journal of information systems research and innovation, 2013.

Al-rahmi,W and Othman, M. (2013c). Using TAM Model to Measure the Use of Social Media for Collaborative Learning. International Journal of Engineering Trends and Technology (IJETT), 2013.

Astin,W.(1984).Student Involvement: A Developmental Theory for Higher Education" 1984, (July), 518-529.

Barnes, G, and Lescault, A. (2011).The 2011 inc. 500 social media update: Blogging de-clines as newer tools rule, Center for Marketing Research Charlton College of Business: University of Massachusetts Dartmouth. 2011.

Borau, K. Ullrich, C. Feng, J. and Shen, R. (2009).Microblogging for language learning: Using twitter to train communicative and cultural competence, Advances in Web Based Learning-ICWL 2009, 78-87.

Boyd,M., and Ellison,B(2007).Social network sites: Definition, history, and scholarship", Journal of Computer-Mediated Communication, 2007, 13(1), 210-230.

ComScore.(2011).State of the U.S. social networking market: Facebook maintains leader-ship position, but upstarts gaining traction, 2011.

Davis,D. Bagozzi, P. and Warshaw, P. (1989).User acceptance of computer technology: a comparison of two theoretical models, Journal of Management Science, 1989.

Deng, L and Yuen, K. (2011).Towards a framework for educational affordances of blogs", Computers \& Education, 2011, 56(2), $441-451$.

Dunlap,C. and Lowenthal, R. (2009).Tweeting the night away: Using Twitter to enhance social presence, Journal of Information Systems Education, 2009, 20(2), 129-135.

Gruzd,A, Staves, K., and Wilk, A.(2011). Tenure and promotion in the age of online social media", Proceedings of the American Society for Information Science and Tech-nology, 2011, 48(1), 1-9.

Heiberger,G. and Harper, R. (2008).Have You Facebooked Astin Lately? Using Technol-ogy to Increase Student Involvement.2008, (124).

Higher Education Research Institute,(2007).College freshmen and online social net-working sites.2007.

Huang,C. Huang, Y. and Yu, Y. (2011).Cooperative weblog learning in higher education: Its facilitating effects on social interaction, time lag, and cognitive load, Educa-tional Technology \& Society, 2011,14(1), 95-106.

Hung, H. and Yuen, S. (2010).Educational use of social networking technology in higher education, Teaching in Higher Education, 2010, 15(6), 703714.

Irwin,C., Ball, L. Desbrow, B. and Leveritt, M. (2012).Students' perceptions of using Fa-cebook as an interactive learning resource at university, Australasian Journal of Educational Technology, 2012, 28(7), 1221-1232.

Joosten,T. (2012). Social media for educators: Strategies and best practices, Hoboken, NJ, USA: Jossey-Bass.2012.

Junco,R.(2012).The relationship between frequency of Facebook use, participation in Facebook activities, and student engagement, Computers \& Education, 2012, 58.

Kaplan,A., and Haenlein,M.(2010).Users of the world, unite! The challenges and opportu-nities of social media, Business Horizons, 2010.53(1), 59-68.

Kim,S. Park, B. and Oh, J. (2008).An examination of factors influencing consumer adop-tion of short message service (SMS), Psychology \& Marketing, 2008, 25, 769-786.

Kim,W. Chan, C. and Gupta, S. (2007).Value-based adoption of mobile internet: An em-pirical investigation", Decision Support Systems, 2007, 43, 111-126.

Kwon,O. and Wen, Y. (2010).An empirical study of the factors affecting social network service use, Computers in Human Behavior, 2010, 26, $254-263$.

Lenhart,A., Purcell, K. Smith,K., and Zickuhr, K. (2010)Social media and mobile internet use among teens and young adults, Washington, DC: Pew Internet \& American Life Project.2010.

Madge, C., Meek, J. Wellens, J. and Hooley, T.(2009).Facebook, social integration and informal learning at university: It is more for socializing and talking to friends about work than for actually doing work", Learning, Media and Technology, 2009.

McCarthy,J., (2010).Blended learning environments: Using social networking sites to en-hance the first year experience, Australasian Journal of Educational Technology, 2010, 26(6), 729-740.

Medlin,B. and Green, W. (2009).Enhancing performance through goal setting, engage-ment, and optimism. Industrial management Dan data systems, 2009.

Moon.J, and Kim, Y. (2001).Extending the TAM for a world-wide-web context, Infor-mation Management 2001, 217-230.

Papacharissi,Z.(2009).The virtual geographies of social networks: A comparative analy-sis of Facebook, Linkedln and ASmallWorld", New Media \& Society, 2009.

Selim,M.(2003).An Empirical Investigation of Student Acceptance of Course Websites", Computers and Education, 2003, 40(4), 343-60.

Selwyn,H. Neil, and Grant, L. (2009).Researching the realities of social software use - an introduction, Learning, Media and Technology, 2009, 34(2), 79-86.

Sim, S and Hew, F. (2010).The use of weblogs in higher education settings: A review of empirical research, Educational Research Review, 2010, 5(2), 151-163.

So,J and Brush, A. (2008).Students perceptions of collaborative learning, social pres-ence and satisfaction in a blended learning environment: relationships and critical factors, Computers \& Education, 2008, 51(1), 318.

Top,E.(2012).Blogging as a social medium in undergraduate courses: Sense of commu-nity best predictor of perceived learning, The Internet and Higher Education, 2012.

Venkatesh,V. and Bala, H.(2008).Technology Acceptance Model 3 and a research agenda on interventions, Journal of Decision Sciences, 2008.

Venkatesh, V. Morris, G. Davis, B. and Davis, D. (2003).User acceptance of information technology: Toward a unified view", MIS Quarterly, 2003,27(3), 425-478. 